revista docência do ensino

\title{
Sala de aula invertida no ensino remoto de Química Geral
}

\author{
Julliane D. Yoneda ${ }^{1}$ \\ José Augusto Oliveira Huguenin ${ }^{2}$
}

\section{RESUMO}

Com a pandemia da covid-19 e a necessidade de implementação do ensino remoto, diversas estratégias têm sido elaboradas na tentativa de minimizar os danos acarretados ao processo de ensino-aprendizagem. Nesse contexto, este trabalho apresenta o desenvolvimento e a implementação de uma metodologia que mostrou resultados positivos na disciplina de Química Geral, ofertada, em modalidade remota, para ingressantes dos cursos de bacharelado em Química Tecnológica e licenciatura em Química, visando aprimorar o processo de ensino-aprendizagem e motivar os alunos para que estudem continuamente. São empregados recursos digitais em uma sequência, que coloca o aluno como protagonista, dando-lhe autonomia sem deixá-lo desassistido. Essa metodologia também pode ser aplicada no ensino presencial como ferramenta de ensino em metodologias ativas, e ser adaptada para diferentes disciplinas, com foco no despertar da curiosidade, do interesse em aprender e, consequentemente, da motivação dos discentes.

Palavras-chave: Ensino remoto emergencial. Tecnologias digitais. Ensino de Química. Sala de aula invertida.

\section{Como citar este documento - ABNT}

YONEDA Julliane D.; HUGUENIN, José Augusto Oliveira. Sala de aula invertida no ensino remoto de Química Geral. Revista Docência do Ensino Superior, Belo Horizonte, v. 11, e034550, p. 1-23, 2021. DOI: https://doi.org/10.35699/22375864.2021.34550.

Recebido em: 16/06/2021 Aprovado em: 19/08/2021 Publicado em: 20/12/2021

\footnotetext{
${ }^{1}$ Universidade Federal Fluminense (UFF), Volta Redonda, RJ, Brasil. ORCID ID: https://orcid.org/0000-0001-7978-8686. E-mail: jullianeyoneda@id.uff.br ${ }^{2}$ Universidade Federal Fluminense (UFF), Volta Redonda, RJ, Brasil. ORCID ID: https://orcid.org/0000-0001-7410-4281.E-mail: jose_huguenin@id.uff.br
} 


\section{Aula invertida en la enseñanza remoła de Química General}

\section{RESUMEN}

Con la pandemia del covid-19 y la necesidad de implementar el aprendizaje a distancia, se han desarrollado varias estrategias para tratar de minimizar el daño causado al proceso de enseñanza-aprendizaje. En este contexto, presentamos el desarrollo e implementación de una metodología que arrojó resultados positivos en la disciplina de Química General, ofrecida, en modalidad remota, a los estudiantes de los cursos de Química Tecnológica y licenciatura en Química, con el objetivo de mejorar el proceso de aprendizaje y motivar a los alumnos a estudiar de forma continua. Los recursos digitales se utilizan en una secuencia que coloca al alumno como protagonista, otorgándole autonomía sin dejarlo desatendido. La metodología también se puede aplicar en la enseñanza presencial como herramientas de enseñanza en metodologías activas y se puede adaptar a diferentes disciplinas, centrándose en el despertar de la curiosidad, el interés por aprender y, en consecuencia, la motivación de los estudiantes.

Palabras clave: Enseñanza remota de emergencia. Tecnologías digitales. Didáctica de la Química. Aula invertida.

\section{Flipped classroom in remote learning of General Chemistry}

\section{ABSTRACT}

With the covid-19 pandemic and the need to implement remote learning, several strategies have been developed in order to minimize the damage caused to the teaching-learning process. In this context, this work presents the development and implementation of a methodology that showed positive results in the discipline of General Chemistry offered in remote learning to freshmen of the Bachelor of Technological Chemistry and the Licentiate Degree in Chemistry courses, aiming to improve the teaching-learning process and motivate students to study continuously. Digital resources are used in a sequence that places the student as the protagonist, giving them autonomy without leaving them unattended. This methodology can also be applied in face-to-face learning as teaching tools in active methodologies, as well as being adapted to different disciplines, focusing on the awakening of curiosity, the interest in learning and, consequently, the motivation of students.

Keywords: Emergencial remote learning. Digital technologies. Chemistry's teaching. Flipped classroom. 


\section{INTRODUÇÃO}

Em meio à pandemia de covid-19, os professores buscam se adaptar, se reinventar, e aprender novas tecnologias e metodologias para ensinar, motivar seus alunos e tornar efetivo o processo de ensino-aprendizagem na modalidade remota. Considerando as chamadas tecnologias digitais (TDs), é crescente o número de trabalhos que já apontavam para o sucesso de sua utilização no ensino superior, mesmo antes da pandemia. As mídias sociais mostram-se úteis como ferramenta de grande alcance no processo de ensino (CELESTINO et al., 2019). No ensino de Química, são muitas as possibilidades de uso dessas tecnologias (LEITE, 2015), podemos citar o desenvolvimento e aplicação de jogos (LIMA; MOITA, 2011) e o uso de softwares matemáticos em aulas de Química (SANDES; AMBROSIO; ANGELUCCI, 2013). Recentemente, foi proposta uma abordagem interdisciplinar entre disciplinas de Química Geral e Computação para o ensino de conteúdos de Química (YONEDA; HUGUENIN, 2018).

Metodologias ativas de ensino são aquelas que buscam o protagonismo dos estudantes no processo de ensino-aprendizagem (DIESEL; BALDEZ; MARTINS, 2017) em contraposição ao ensino centrado nos professores e ao método tradicional (MOREIRA, 2011). Estudos apontam que métodos ativos de ensino, nos quais o estudante tem protagonismo nos processos educativos, têm gerado excelentes resultados. Um estudo nos Estados Unidos, em cursos de Ciências, Engenharias e Matemática (STEM), mostrou que a reprovação em disciplinas que usam métodos tradicionais é de $34 \%$ e para aquelas que usam métodos ativos é de 22\% (FREEMAN et al., 2014). Estudos também mostram melhoria no ensino com o emprego de métodos ativos em cursos superiores no Brasil (TREVELIN; PEREIRA; OLIVEIRA NETO, 2013). Cada vez mais difundido, pode-se encontrar propostas do uso de Sala de Aula Invertida (SAI) em todos os níveis escolares (PAIVA et al., 2016).

Dentre os métodos ativos mais conhecidos, podemos citar: o método de Instrução por Pares (Peer instructions), que se baseia na interatividade entre os alunos e é muito eficaz para compreensão de conceitos (MAZUR, 1991); o método de Sala de Aula Invertida (Flipped Classroom), em que os alunos estudam por meio de materiais de autoinstrução antes da aula; o Ensino sob Medida (Just-in time teaching), que se baseia em conhecer previamente as dificuldades dos alunos para a preparação da aula (NOVAK et al., 1999); e o método de Aprendizado Baseado em Problemas (Problem Based Learning), muito utilizado nas áreas médicas, mas também aplicado em cursos tecnológicos de Engenharia (FREITAS, 2012). Desde 2020, com a necessidade de implementação do ensino remoto emergencial, diversas estratégias têm sido elaboradas na tentativa de minimizar os danos acarretados pela pandemia ao processo de ensino-aprendizagem (NEVES; VALDEGIL; SABINO, 2021; PALMEIRA; RIBEIRO; SILVA, 2020), e o uso de TDs tornou-se essencial (SANTOS, 2021; ALMEIDA, 2020). Nesse contexto, este trabalho apresenta o desenvolvimento e implementação de uma metodologia que mostrou resultados positivos na disciplina de 
Química Geral, ofertada, em modalidade remota, para ingressantes dos cursos de bacharelado em Química Tecnológica e licenciatura em Química, visando aprimorar o processo de ensino-aprendizagem e motivar os alunos para que estudem continuamente. $O$ desenvolvimento do projeto é apresentado, ressaltando sua estratégia tanto para melhoria do viés de participação e desempenho dos estudantes, quanto da sua formação acadêmica. A implementação do método é apresentada e discutida em detalhes, destacando-se os pontos positivos e negativos avaliados pelos alunos. Por fim, nas considerações finais, elenca-se os principais resultados obtidos.

\section{MÉTODOS ATIVOS E TEORIAS DE APRENDIZAGEM}

O chamado método tradicional se baseia na estrutura narrativa centrada no professor, que detém totalmente as ações de ensino, enquanto aos alunos, que passivamente assistem a narrativa, cabe o processo de aprendizagem (MOREIRA, 2011). Paulo Freire denominou esse tipo de ensino como "educação bancária", com o professor "depositando" os conteúdos na estrutura cognitiva dos alunos (FREIRE, 2013). Na maioria dos casos, esses processos ocorrem isoladamente, com os alunos reclamando de aulas cansativas e docentes se queixando do não envolvimento dos alunos (DIESEL; BALDEZ; MARTINS, 2017).

O pensamento freiriano aponta que a educação não é um processo particionado, isolado, em que ao professor cabe o ensino e ao aluno o aprendizado, mas acontece na interação dos sujeitos envolvidos e temos um único processo, o processo de ensino-aprendizagem (FREIRE, 2015). Nessa perspectiva, podemos dizer que um método ativo é aquele que as ações dos alunos são planejadas para que eles participem ativamente das etapas de ensino, estimulando a autoaprendizagem. Nesse método, o professor tem um papel de mediação na interação entre os alunos e os conhecimentos a serem ensinados (DIESEL; BALDEZ; MARTINS, 2017).

Várias teorias de aprendizagem suportam a prática de métodos ativos. Podemos começar citando Vygotsky, para o qual a aprendizagem se dá pela interação social a partir da interação entre aluno e professor e por pares (VYGOTSKY, 2007). Outro grande nome da psicologia educacional, John Dewey, valorizava o aprendizado pela experiência, pensamento que fundou o movimento "Escola Nova", onde os estudantes estão no centro do processo de ensino, fazendo com que a aprendizagem ocorra pela ação (DEWEY, 1978). Podemos ir além, chegando à Teoria de Aprendizagem Significativa de David Ausubel que aponta a predisposição ao aprendizado como um elemento imprescindível no processo (AUSUBEL, 1968). Muitas vezes a potencialização dessa predisposição se dá por meio do engajamento do aluno a partir de participação ativa. As já citadas teorias de Paulo Freire, ao valorizarem a interação social e o uso da realidade dos alunos como elemento de engajamento, recorrendo à pedagogia problematizadora, são um suporte amplo para implementação de métodos ativos de ensino. 
Como é possível verificar, os métodos ativos são suportados e até indicados por importantes teorias de aprendizagem, o que os habilitam como alternativa na busca por melhorias no ensino. Na próxima seção é discutido o método ativo utilizado nesta proposta, o método da SAI.

\section{SALA DE AULA INVERTIDA}

Desenvolvido por Bergmann e Sams (2012), o método de SAI é um exemplo de metodologia ativa de ensino. Visando cobrir o ensino para alunos que frequentavam pouco as aulas, os autores passaram a postar, em ambiente virtual, materiais como vídeos e textos. Os alunos que frequentavam as aulas também passaram a acessar esse material, o que provocou uma mudança expressiva na sala de aula.

Esse método nasceu na prática docente, não sendo concebido a partir de um referencial teórico específico. Como discutido na seção anterior, como método ativo, a SAI pode ser compreendida a partir de diferentes pontos de vista. Martin e Martins (2018) apresentaram uma sequência didática para o ensino do conceito de equilíbrio químico na disciplina de Química Geral Experimental, onde usaram a Teoria da Mediação de Vygotsky (VYGOTSKY, 2007). Tendo em vista que essa teoria preconiza a interação do sujeito com o objeto de estudo a partir da mediação de docentes, as autoras interpretam o método SAI atuante na chamada Zona de Desenvolvimento Potencial de estudantes, uma vez que o protagonismo deles os colocará na frente de situações de aprendizagem que serão mediadas na aplicação de conceitos estudados previamente.

Em uma abordagem teórica mais atual, o método de SAI foi estudado no contexto da Teoria de Carga Cognitiva (SWELLER, 1988) que, em linhas gerais, está relacionada com a quantidade (carga) de informação e memorização requerida na solução de problemas. Abeysekera e Dawson (2015) apresentaram um estudo apontando a Sala de Aula Invertida como potencializador de motivação e gerenciamento de carga cognitiva, uma vez que engaja o aluno no processo ensino-aprendizagem.

Tendo em vista essas ideias, apresenta-se as etapas básicas do método SAI. Os autores sistematizaram o método a partir da identificação de três momentos ou etapas: pré-aula, aula e pós-aula. A seguir, essas etapas são apresentadas de forma sucinta.

i) pré-aula: prepara-se um material voltado a autoinstrução do aluno. Podem ser materiais produzidos pelo professor ou reunidos a partir de uma curadoria de materiais disponíveis. Podem ser videoaulas sobre o conteúdo, textos, vídeos de experimentos e simulações, no caso de ciências. Esse material é estudado previamente fora da sala de aula. 
ii) aula: aqui o professor pode aplicar os conceitos através de situações-problema, onde os alunos poderão fazer atividades mediadas pelo professor. $\mathrm{O}$ docente pode, vendo necessidade, atuar para aparar arestas na compreensão dos alunos.

iii) pós-aula: é um momento voltado à prática dos alunos. No ensino de Química, corresponde à realização de listas de exercícios ou relatórios de experimentos, por exemplo.

$\mathrm{Na}$ literatura encontram-se trabalhos que relatam a aplicação bem-sucedida dessa metodologia no ensino de Química. O uso de atividades pré-aula mostrou uma diminuição na carga cognitiva em cursos de Química no ensino superior (SEERY; DONNELLY, 2012). Reid (2016) propôs um novo design do método de SAI para a disciplina de Química Geral, obtendo excelentes resultados. A postura ativa e o engajamento atitudinal no estudo de Química foi otimizado com o uso de SAI (OLAKANMI, 2017). A aplicação da metodologia em curso de Química Geral também foi analisada do ponto de vista de performance. Foi mostrado por Weaver e Sturtevant (2015) que o desempenho de alunos da disciplina de Química Geral no método de SAI foi muito superior às notas com o método tradicional, resultado também observado por Ryan e Reid (2016). A aplicação da metodologia na disciplina de Química Geral Experimental mostrou-se igualmente eficaz (MARTIN; MARTINS, 2018). Na disciplina de Química Orgânica, a metodologia também foi aplicada com sucesso no estudo do conteúdo de RMN (SILVA; SILVA NETO; LEITE, 2021). Nessa pesquisa, os autores observaram que os estudantes tiveram controle sobre espaço e tempo no estudo do material enquanto o professor contribuiu para que os alunos desenvolvessem a discussão dos conteúdos em sala de forma engajada, o que foi possibilitado pelo estudo prévio. Também no ensino médio encontramos o uso bem-sucedido do método de sala invertida (OLIVEIRA; ROSSI; ALVES, 2020; LIMA-JÚNIOR et al., 2017).

Vale destacar que os trabalhos encontrados na literatura relatam a implementação prépandemia, de forma que as atividades de aula foram presenciais, como preconiza o método SAI. O desafio nessa proposta foi adaptar esse modelo híbrido para a modalidade remota, onde as atividades presenciais tiveram que ser substituídas por encontros síncronos mediante o uso de tecnologias digitais. Considerando o grande percentual de aulas assíncronas no modelo remoto adotado pela instituição, identificou-se que a metodologia de Sala de Aula Invertida (SAI) se adequava muito bem ao propósito de ensino remoto que puxasse pela autonomia e engajamento dos alunos. Na próxima seção, a proposta é apresentada detalhadamente.

\section{A DISCIPLINA DE QUÍMICA GERAL COM APOIO DE TECNOLOGIAS DIGITAIS}

A disciplina de Química Geral (QG) é a base fundamental para as demais disciplinas do curso de Química. A ementa dessa disciplina para os cursos de licenciatura e bacharelado em Química, em geral, é extensa. Além disso, boa parte dos alunos ingressam nesses cursos sem 
ter Química como primeira opção de curso universitário, conforme resultado de enquete feita a cada período pela professora da disciplina. É também observada uma defasagem na base teórica necessária para ingressar em um curso de Ciências Exatas, o que contribui para que o índice de reprovação e a taxa de desistência sejam extremamente elevados nos cursos em que a disciplina QG é oferecida. Essa realidade não é diferente em outros cursos de Química no país (CUNHA; TUNES; SILVA, 2001; JESUS, 2015; MELO; SALDANHA, 2020).

Para enfrentar essa questão, foi desenvolvida uma sequência de procedimentos para os estudantes da disciplina. O fio condutor do projeto foi melhorar o processo de ensinoaprendizagem na disciplina QG, diante da realidade de ensino remoto durante a pandemia da covid-19, bem como motivar os estudantes a participarem das atividades propostas e estudarem continuamente. Para isso utilizou-se um Ambiente Virtual de Atividades (AVA). Foi utilizada a plataforma Google Classroom, que os alunos da Universidade Federal Fluminense têm acesso a partir de suas contas de e-mail institucional, criada em parceria com a Google.

No ensino remoto emergencial a carga horária da disciplina foi dividida em $70 \%$ assíncrona e $30 \%$ síncrona. Logo, os estudantes teriam que dedicar-se ao estudo dos conteúdos sem a presença, mesmo que remota, da professora da disciplina. Essa realidade é adequada para a aplicação da metodologia de Sala de Aula Invertida (BERGMANN; SAMS, 2012). Dessa forma, o curso seguiu a estrutura de SAI. Para a pré-aula, foi preparado material de estudo ou autoinstrução, bem como listas de exercícios de fixação, que compunham as atividades assíncronas do curso. Essas atividades eram realizadas antes de um encontro síncrono semanal, quando acontecia a segunda etapa da SAl: a aplicação dos conteúdos na aula. A diferença aqui foi que esse encontro se deu remotamente pela plataforma do Google Meet. Nesse encontro síncrono, além da discussão de problemas, foi feita uma sistematização dos conteúdos para que arestas na compreensão das temáticas fossem aparadas. Para a etapa pós-aula, foram realizados testes para avaliar o quanto o assunto foi assimilado.

O conteúdo da ementa foi dividido em unidades ou módulos semanais. Na Figura 1 tem-se o painel do módulo referente à Cinética Química. 
Julliane D. Yoneda, José Augusto Oliveira Huguenin

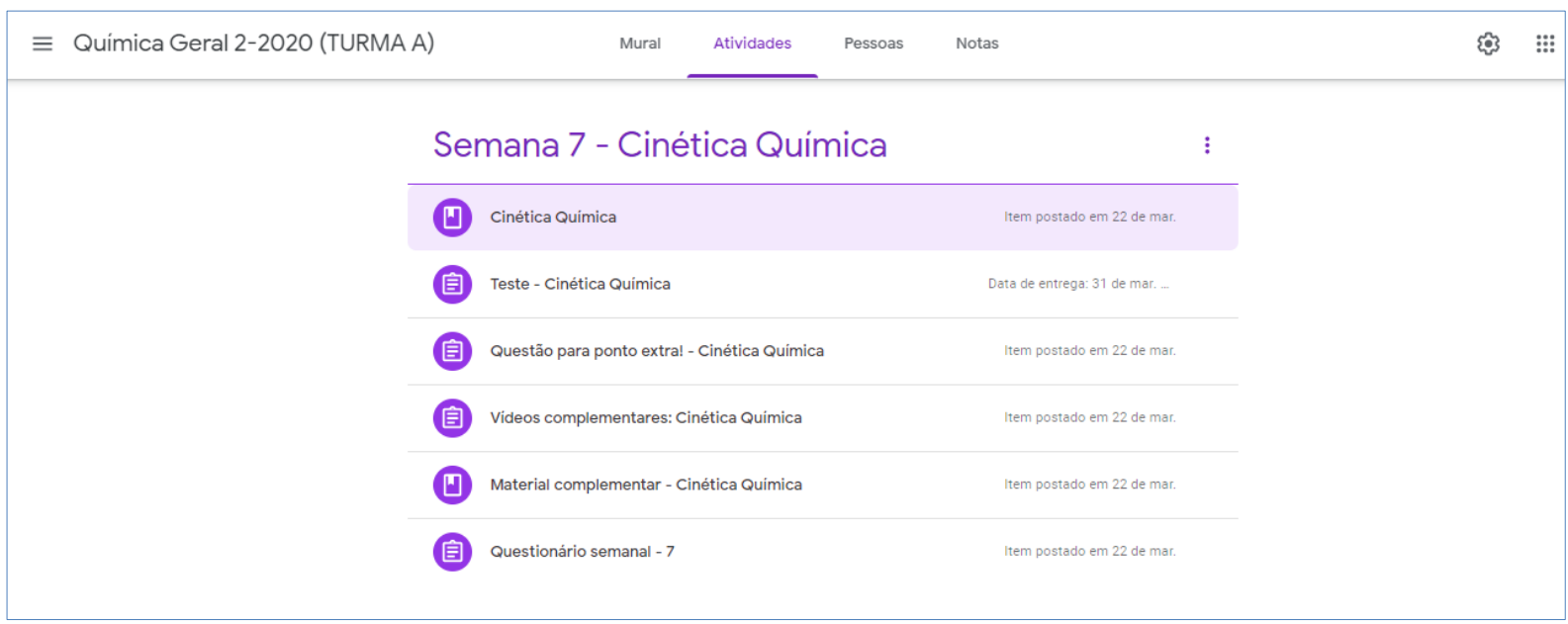

Figura 1 - Módulo referente ao conteúdo de Cinética Química disponibilizado aos alunos no Ambiente Virtual de Aprendizagem (AVA)

Fonte: elaborada pelos autores, 2021.

Dentro de cada módulo, como o da Figura 1, sempre havia seis seções, as quais são descritas a seguir:

- Conteúdo: nessa seção o aluno encontrava o material de estudo da pré-aula. Foram disponibilizadas videoaulas com cerca de 30 minutos em média, elaboradas pela professora da disciplina, além dos slides referentes aos vídeos, para que o aluno pudesse baixá-los em formato PDF e fazer suas anotações. Também foram liberados os slides que seriam utilizados na aula síncrona que ocorreria uma semana após a disponibilização do material, bem como uma lista com exercícios de fixação sobre o assunto;

- Teste semanal: disponibilizado imediatamente após a aula síncrona sobre o conteúdo apresentado, compondo a atividade pós-aula, segundo metodologia de SAI. Tinha como intuito fazer com que o aluno verificasse se estava conseguindo acompanhar o conteúdo semanal e fazer com que este estudasse continuamente (não apenas na véspera da prova, o que é uma atitude muito comum, especialmente entre os alunos ingressantes). A pontuação obtida nesses testes foi contabilizada para o cálculo da média final. O teste era sempre de múltipla escolha, contendo cerca de dez questões, realizado de forma assíncrona via um formulário Google, e podia ser realizado em um intervalo de 48 horas. Ao final, o aluno recebia sua pontuação, bem como o gabarito comentado de cada questão, de modo que o aluno tinha a oportunidade de verificar o que errou, o quanto ele está assimilando ou não o conteúdo da disciplina e detectar os pontos que precisava estudar com mais detalhes;

- Questão aplicada: nessa seção era disponibilizada semanalmente uma questão de resolução opcional com aplicação prática, que instigasse e despertasse o interesse do 
aluno em aprender. As respostas tinham que ser redigidas em cerca de sete linhas. A ideia era motivá-los, mostrando que aquele conteúdo é muito importante não só para a compreensão de questões cotidianas e atuais, como por exemplo, aplicações do conteúdo à situações que envolvem a covid-19, cores dos fogos de artifício, a explosão que ocorreu em Beirute em 2020, mas também para sua atuação profissional, com questões onde o aluno é o químico responsável por resolver problemas, como maximizar a obtenção de um produto industrial valioso, avaliar o prazo de validade de um determinado medicamento ou dar um parecer sobre a viabilidade de se utilizar determinado material para a construção de um reator. Como forma de valorização desse trabalho complementar, foi estabelecida uma pontuação adicional para a atividade, que poderia acrescentar até meio ponto extra à nota final proporcionalmente à pontuação obtida ao longo do curso;

- Vídeos complementares: aqui foram postados links do Youtube que remetiam a vídeos de outras universidades como UNIVESP e Unicamp, por exemplo. Desse modo, o aluno tinha a oportunidade de assistir o mesmo conteúdo com outras formas de apresentação, caso não tivesse se identificado com a forma de exposição realizada pela professora;

- Material complementar: nessa seção buscou-se por materiais que complementassem o conteúdo de modo interessante, que despertasse a curiosidade dos alunos e os ajudasse no processo de construção do conhecimento. Como exemplo, foram disponibilizados links para algumas simulações no Phet Simulations (WIEMAN, s.d.), links de vídeos do Youtube para animações que ilustram interações intermoleculares, como os elétrons se distribuem nos orbitais ou para visualização de uma cela unitária em um sólido iônico. Em cada módulo, havia um resumo do conteúdo elaborado pela monitora da disciplina e, em alguns módulos, vídeos com experimentos em laboratório que ilustravam a teoria estudada ou artigos científicos com aplicações;

- Questionário semanal: semanalmente havia uma avaliação por formulário anônimo, de modo que o aluno tinha liberdade para explicitar o que não era considerado bom na metodologia aplicada, bem como dar sugestões do que poderia ser melhorado.

Apesar da grande quantidade de material, o aluno tinha que acessar, obrigatoriamente, durante a semana, apenas as seções (i) e (ii). Como as outras seções eram opcionais, o aluno tinha disponibilidade de visitá-las ao longo do curso, em momento que considerasse mais apropriado.

Vale comentar que para a realização das aulas síncronas, a turma, que era composta por cerca de 45 alunos, foi dividida em três grupos (três salas virtuais no Google Classroom com 15 alunos em cada uma). Assim, a disciplina de 6 horas semanais era cursada por cada aluno 
de forma $30 \%$ síncrona e $70 \%$ assíncrona. A professora se encontrava pela plataforma Google Meet uma vez por semana com cada grupo durante duas horas, e neste momento síncrono, apresentava uma síntese do conteúdo semanal, bem como resolvia exercícios para fixação do conteúdo e estimulação do pensamento crítico-reflexivo. Com grupos reduzidos é possível ter uma proximidade maior com cada aluno e estes, por sua vez, têm mais espaço para interação e exposição de dúvidas e questionamentos. As aulas síncronas eram gravadas e disponibilizadas no AVA para que os estudantes que não pudessem comparecer, tivessem a oportunidade de assistir depois, bem como os estudantes que participaram, pudessem rever a aula com calma quando quisessem, retornando nos trechos que eventualmente não tivessem ficado muito claros durante a aula síncrona.

Além deste $A V A$, o aluno interessado ainda podia ter o apoio do monitor, disponível para atendimento em outro AVA por seis horas semanais, e atendimento fora do horário de aula com a professora, disponibilidade de uma hora semanal em uma sala virtual do Google Meet.

A ementa foi dividida em três partes, de forma a se ter três provas discursivas realizadas de forma síncrona. Antes de cada uma dessas provas, havia sempre uma aula síncrona para esclarecimento de dúvidas. A nota final foi calculada pela seguinte relação:

$$
\text { Nota final }=(\text { Média das provas*0,7) }+(\text { Média dos testes*0,2) }+(\text { Trabalho*0,1), }
$$

onde o trabalho consistia em uma resenha sobre radioatividade e suas aplicações. $\mathrm{O}$ uso das atividades feitas pelos alunos ao longo do semestre como parte da avaliação está de acordo com processos de avaliação continuada (HOFFMANN, 2009).

Ao final do curso, um questionário final de avaliação geral do curso foi aplicado, também com respostas não identificadas. O questionário é apresentado no apêndice deste trabalho.

Na Figura 2 apresenta-se um esquema geral de funcionamento da metodologia empregada. 


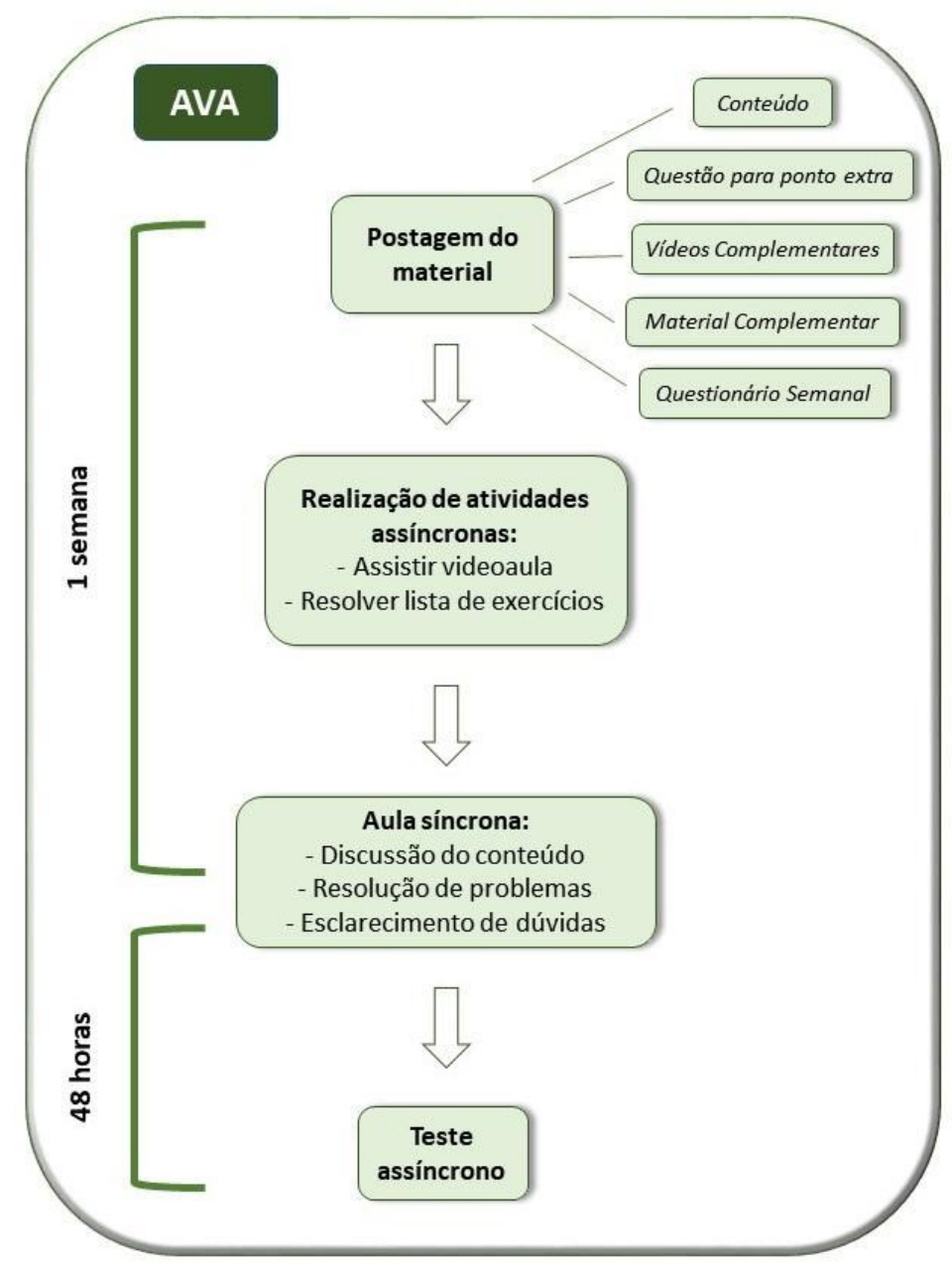

Figura 2 - Esquema da metodologia implementada para cada módulo mediada por um Ambiente Virtual de Aprendizagem (AVA)

Fonte: elaborada pelos autores, 2021.

\section{APLICAÇÃO DA METODOLOGIA E RESULTADOS}

A metodologia foi implementada nos períodos correspondentes ao primeiro e segundo semestres letivos de 2020.

Os questionários semanais nortearam a professora sobre como aprimorar a metodologia de modo a atender a um número cada vez maior de alunos. Pontos simples, como utilizar slides de fundo claro, preferência de cerca de $70 \%$ dos alunos, ou escuro nas videoaulas, foram atendidos com pelo menos uma videoaula realizada com slide de fundo escuro a cada três ou quatro com fundo claro. Outros pontos, como por exemplo, incluir resolução de exercícios nas videoaulas e colocar mais textos nos slides, contribuíram não só para incrementar a metodologia, mas também para melhorar o processo de ensino-aprendizagem de acordo com o retorno obtido por parte dos alunos. 
Com relação ao questionário final de avaliação do curso, 23 alunos de 35 (66\%) não desistentes responderam ao questionário no período referente ao primeiro semestre de 2020. Já no período referente ao segundo semestre, 18 de 24 alunos não desistentes (75\%) responderam. Como resultado da avaliação, praticamente $100 \%$ dos alunos respondentes avaliaram que a troca de questionários semanais contribuiu de forma positiva para atender às necessidades da turma, apenas um aluno do primeiro semestre considerou que não contribuiu.

A avaliação dos alunos foi positiva em todos os aspectos. Em uma escala de 0 a 5 , a metodologia foi avaliada com nota 5 por $78 \%$ dos respondentes em ambos os semestres, não houve avaliações com notas entre 0 e 2 . Apenas um aluno avaliou a metodologia do curso com nota 3 no primeiro semestre.

A Figura 3 mostra a avaliação com relação aos materiais e vídeos complementares e também com relação à metodologia e o incentivo para permanência no curso. É possível verificar, em ambos os semestres, que nenhum aluno julgou o material desnecessário e a grande maioria ou sentiu que o material ajudou no processo de ensino-aprendizagem ou considerou que o material complementou satisfatoriamente o conteúdo. Além disso, mais da metade dos alunos considerou que a metodologia contribuiu bastante para a sua permanência até o final do curso. 

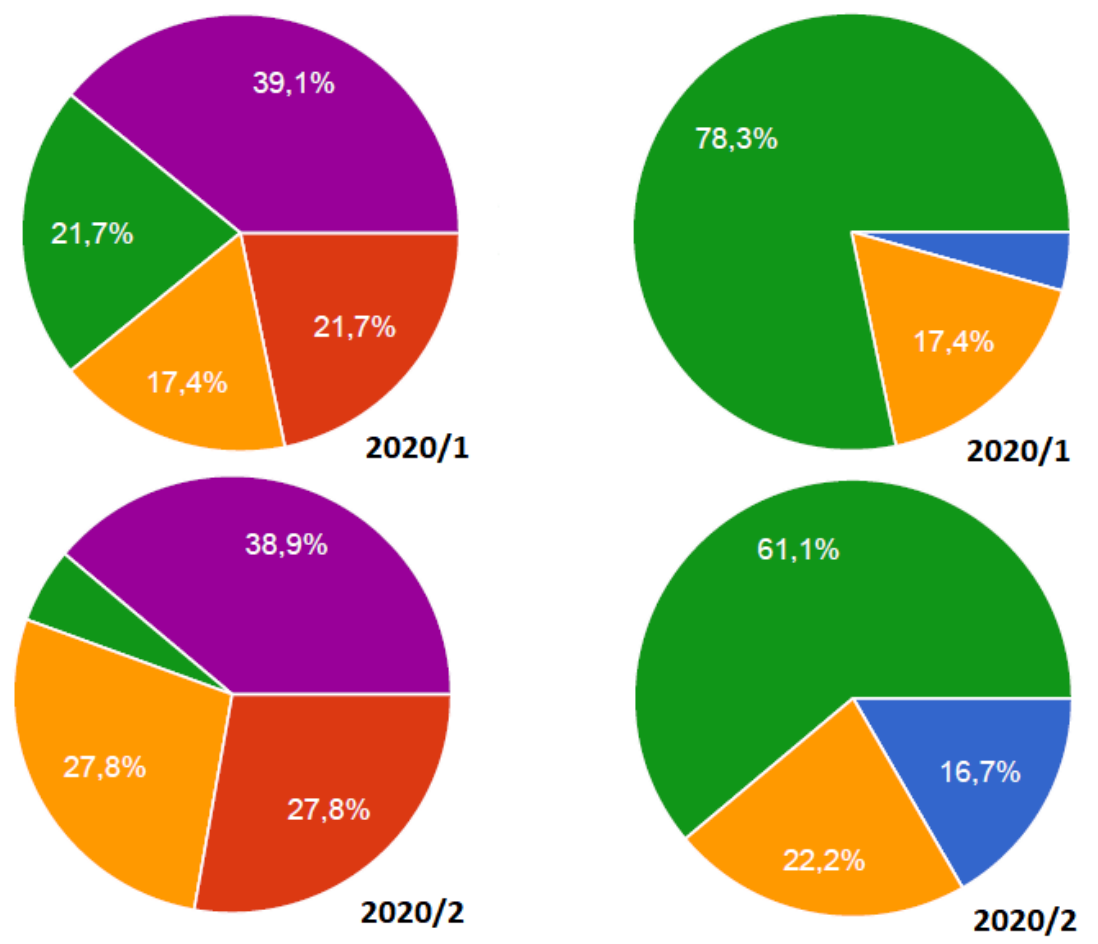

Desnecessários

Foi indiferente

Me ajudaram um pouco

Me ajudaram bastante

Interessantes, mas não utilizei

Interessantes e complementaram bastante o conteúdo

(a)

(b)

Figura 3 - Respostas dos alunos às seguintes perguntas: (a) O que você achou dos materiais e vídeos complementares? (b) A metodologia utilizada te incentivou a ficar até o final do curso?

Fonte: elaborada pelos autores, 2021.

No que tange aos testes semanais e questões de ponto extra, a Figura 4 apresenta as respostas coletadas. Pode-se constatar que a imensa maioria dos alunos gostou dessas atividades, seja porque contribuíram para a nota final seja porque não deixaram a matéria acumular ou permitiram ver a aplicabilidade do conteúdo estudado. 

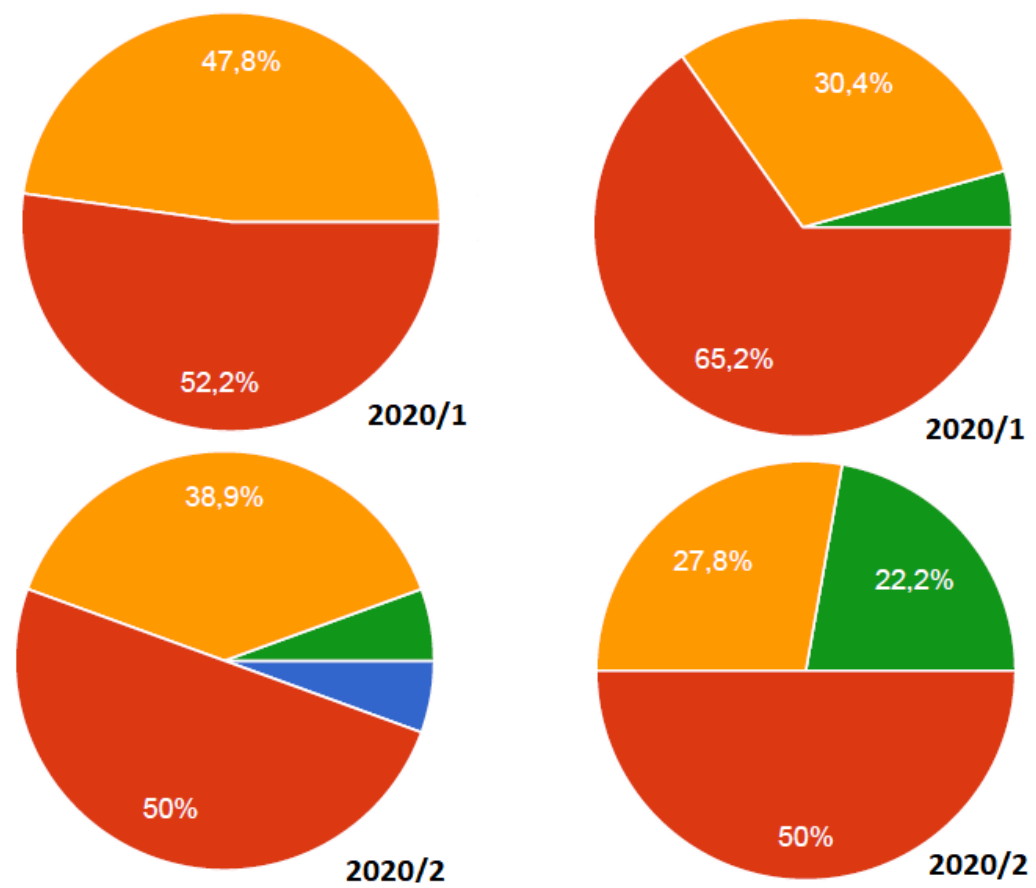

Não gostei

Gostei, pois não deixaram que a matéria acumulasse

Não gostei

Gostei, pois me fizeram ver a aplicabilidade dos conteúdos estudados

Gostei, pois contribuíram para a nota final de forma positiva

Indiferente

(a)

Gostei, pois contribuíram para a nota final de forma positiva

Indiferente

(b)

Figura 4 - Respostas dos alunos às seguintes perguntas: (a) O que você achou dos testes semanais como parte da avaliação? (b) O que você achou das questões de ponto extra? Fonte: elaborada pelos autores, 2021.

Também foi solicitado que os discentes pontuassem aspectos positivos e negativos da metodologia empregada. Dentre os pontos positivos, pode-se destacar a organização do AVA, a divisão da turma em grupos, a retomada, nas aulas síncronas, dos principais pontos do conteúdo apresentados nas aulas assíncronas, o material disponibilizado e a possibilidade de opinar e dar sugestões com relação à metodologia aplicada. Já alguns dos pontos negativos apontados foram o tempo para resolução dos testes e o fato da prova ser síncrona. É importante salientar que o tempo de 48 horas para resolução dos testes foi pensado com o intuito de evitar o acúmulo de conteúdo. A liberação do conteúdo era imediatamente após a aula síncrona para que o aluno tirasse todas as suas dúvidas e finalizasse o estudo daquele módulo e pudesse então passar para o módulo seguinte.

A Tabela 1 apresenta um panorama quantitativo de alunos desistentes, aprovados e reprovados. O destaque é para a maior percentagem de alunos não desistentes nos períodos em que a metodologia foi implementada: período remoto emergencial - 2020/1 e 2020/2, 
onde, mesmo com todas as dificuldades da modalidade remota, a evasão de alunos ingressantes diminuiu de forma considerável.

Considerando o desempenho, é possível verificar que o percentual de aprovados dos ingressantes no primeiro semestre é, em geral, maior do que no segundo semestre. Nesse contexto, o melhor desempenho ocorreu em 2020/1, quando a metodologia foi implementada. O desempenho em 2020/2 foi o segundo melhor dentre os ingressantes no segundo semestre letivo.

Tabela 1 - Quantitativo de alunos matriculados, desistentes, aprovados e reprovados na disciplina de Química Geral do primeiro semestre de 2017 ao segundo semestre de 2020

Fonte: elaborada pelos autores, 2021.

\begin{tabular}{|c|c|c|c|c|c|c|c|c|}
\hline & $2017 / 1$ & $2017 / 2$ & 2018/1 & $2018 / 2$ & 2019/1 & $2019 / 2$ & $2020 / 1$ & $2020 / 2$ \\
\hline $\begin{array}{c}\text { Alunos } \\
\text { matriculados }\end{array}$ & 57 & 45 & 54 & 51 & 64 & 42 & 52 & 43 \\
\hline $\begin{array}{c}\text { Nunca } \\
\text { compareceram* }\end{array}$ & 4 & 4 & 3 & 2 & 5 & 5 & 13 & 11 \\
\hline Alunos efetivos & 53 & 41 & 51 & 49 & 59 & 37 & 39 & 32 \\
\hline $\begin{array}{c}\text { Desistentes } \\
* *\end{array}$ & $\begin{array}{c}24 \\
(45,3 \%)\end{array}$ & $\begin{array}{c}15 \\
(36,6 \%)\end{array}$ & $\begin{array}{c}20 \\
(39,2 \%)\end{array}$ & $\begin{array}{c}26 \\
(53,1 \%)\end{array}$ & $\begin{array}{c}24 \\
(40,7 \%)\end{array}$ & $\begin{array}{c}15 \\
(40,5 \%)\end{array}$ & $\begin{array}{c}4 \\
(10,3 \%)\end{array}$ & $\begin{array}{c}8 \\
(25,0 \%)\end{array}$ \\
\hline $\begin{array}{c}\text { Não desistentes } \\
* * *\end{array}$ & $\begin{array}{c}29 \\
(54,7 \%)\end{array}$ & $\begin{array}{c}26 \\
(63,4 \%)\end{array}$ & $\begin{array}{c}31 \\
(60,8 \%)\end{array}$ & $\begin{array}{c}23 \\
(46,9 \%)\end{array}$ & $\begin{array}{c}35 \\
(59,3 \%)\end{array}$ & $\begin{array}{c}22 \\
(59,5 \%)\end{array}$ & $\begin{array}{c}35 \\
(89,7 \%)\end{array}$ & $\begin{array}{c}24 \\
(75 \%)\end{array}$ \\
\hline $\begin{array}{c}\text { Aprovados } \\
* * * *\end{array}$ & $\begin{array}{c}18 \\
(62,1 \%)\end{array}$ & $\begin{array}{c}9 \\
(34,6 \%)\end{array}$ & $\begin{array}{c}15 \\
(48,4 \%)\end{array}$ & $\begin{array}{c}10 \\
(43,5 \%)\end{array}$ & $\begin{array}{c}18 \\
(51,4 \%)\end{array}$ & $\begin{array}{c}14 \\
(63,6 \%)\end{array}$ & $\begin{array}{c}26 \\
(74,3 \%)\end{array}$ & $\begin{array}{c}11 \\
(45,8 \%)\end{array}$ \\
\hline $\begin{array}{c}\text { Reprovados } \\
* * * *\end{array}$ & $\begin{array}{c}11 \\
(37,9 \%)\end{array}$ & $\begin{array}{c}17 \\
(65,4 \%)\end{array}$ & $\begin{array}{c}16 \\
(51,6 \%)\end{array}$ & $\begin{array}{c}13 \\
(56,5 \%)\end{array}$ & $\begin{array}{c}17 \\
(48,5 \%)\end{array}$ & $\begin{array}{c}8 \\
(36,4 \%)\end{array}$ & $\begin{array}{c}9 \\
(25,7 \%)\end{array}$ & $\begin{array}{c}13 \\
(54,2 \%)\end{array}$ \\
\hline
\end{tabular}

* Não fizeram nenhuma avaliação; ** Fizeram algumas avaliações apenas; *** Fizeram todas as provas; $* * * *$ Percentual com relação aos não desistentes.

Além da metodologia, observou-se que a afetividade entre aluno e professor mostrou-se um fator extremamente relevante para que, mesmo no modo remoto e com todas as dificuldades que estamos vivenciando, o aluno se sentisse compreendido e acolhido. Isso ficou evidente em vários relatos, como nos apresentados a seguir:

"O curso foi muito bom, você foi compreensiva com a gente" (Entrevistado $1)$.

"Mesmo à distância, nós tivemos total amparo e me senti acolhida" (Entrevistado 2).

"Avaliei o curso com nota 5, pois não foi apenas a metodologia aplicada que gostei, mas também a atenção da professora com nós alunos" (Entrevistado $3)$. 
"Pelo fato de haver tanto empenho seu em aplicar os conteúdos além do carinho e paciência que teve com a gente, fez com que (pelo menos eu) me sentisse acolhida e motivada a continuar no curso mesmo com todas as dificuldades do ensino remoto, sinto que adquiri uma ótima base para prosseguir daqui em diante" (Entrevistado 4).

Em comparação aos resultados de outros trabalhos, como observado por Weaver e Sturtevant (2015) e por Ryan e Reid (2016), notou-se uma melhoria expressiva no engajamento, além de uma redução drástica na evasão do curso. Além disso, comparativamente, o melhor desempenho do curso foi obtido com a aplicação do método. Do ponto de vista do ensino de Química, o material de estudo prévio permitiu a inclusão de questões contextualizadoras com problemas atuais como a pandemia da covid-19 e a explosão que ocorreu em Beirute em 2020, mostrando aplicações potenciais de assuntos como interações intermoleculares, reações químicas e estequiometria.

\section{CONSIDERAÇÕES FINAIS}

Sumarizando, apresentou-se neste trabalho um relato de experiência a partir da implementação de uma nova proposta metodológica na disciplina de Química Geral em um AVA baseada na adaptação da metodologia de Sala de Aula Invertida (SAI) em modalidade de ensino remoto.

A partir dos questionários de avaliação semanais respondidos pelos alunos, foi possível adequar a metodologia às necessidades da turma, de modo que ao final do curso se obteve uma avaliação muito positiva da proposta, além de redução da taxa de desistência em permanecer no curso. Mostrou-se ainda que a afetividade no relacionamento entre professor e aluno contribui para que o estudante se mantenha motivado ao longo do período.

Essa metodologia pode ser adequada a diferentes disciplinas, mantendo como foco o despertar da curiosidade, do interesse em aprender e, consequentemente, da motivação dos discentes. As aplicações práticas da teoria são fundamentais para esse processo, seja por meio de vídeos, simuladores ou questões em que o aluno se torna protagonista na construção do conhecimento. $E$ no momento em que estamos vivendo, também se torna essencial a busca constante por tentar atender, na medida do possível, às necessidades dos alunos, numa tentativa de se minimizar os impactos causados não só pelo distanciamento trazido pelo ensino remoto emergencial, mas também todas as dificuldades encontradas em meio à pandemia. 


\section{REFERÊNCIAS}

ABEYSEKERA, Lakmal; DAWSON, Phillip. Motivation and cognitive load in the flipped classroom: definition, rationale and a call for research. Higher Education Research and Development, v. 34, p. 1-14, 2015. Disponível em:

https://www.tandfonline.com/doi/abs/10.1080/07294360.2014.934336. Acesso em: 13 ago. 2021. DOI: https://doi.org/10.1080/07294360.2014.934336.

ALMEIDA, Maria Claudice Rocha. Práticas pedagógicas mediadas por tecnologias digitais em período de pandemia. Revista Docência do Ensino Superior, Belo Horizonte, v. 10, p. 1-20, 2020. Disponível em: https://periodicos.ufmg.br/index.php/rdes/article/view/24827. Acesso em: 13 ago. 2021. DOI: https://doi.org/10.35699/2237-5864.2020.24827.

AUSUBEL, David Paul. Educational psychology: a cognitive view. New York: Holt, Rinehart and Winston, 1968.

BERGMANN, Jonathan; SAMS, Aaron. Flip Your Classroom: reach every student in every class every day. Washington, DC: International Society for Technology in Education, 2012.

CELESTINO, Marcelo Silva et al. As mídias sociais no contexto da educação superior. Informática na Educação:Teoria \& Prática, Porto Alegre, v. 22, n. 2, p. 210-228, 2019. Disponível em: https://seer.ufrgs.br/InfEducTeoriaPratica/article/view/91646. Acesso em: 13 ago. 2021. DOI: https://doi.org/10.22456/1982-1654.91646.

CUNHA, Aparecida Miranda; TUNES, Elizabeth; SILVA, Roberto Ribeiro da. Evasão do curso de Química da Universidade de Brasília: a interpretação do aluno evadido. Química Nova, São Paulo, v. 24, n. 2, p. 262-280, 2001. Disponível em:

http://www.sbq.org.br/publicacoes/quimicanova/qnol/2001/vol24n2/18.pdf. Acesso em: 13 ago. 2021.

DEWEY, John. Vida e educação. 10. ed. São Paulo: Melhoramentos, 1978.

DIESEL, Aline; BALDEZ, Alda Leila Santos; MARTINS, Silvana Neumann. Os princípios das metodologias ativas de ensino: uma abordagem teórica. Revista Thema, Pelotas, v. 14, n.1, p. 268-288, 2017. Disponível em:

https://periodicos.ifsul.edu.br/index.php/thema/article/view/404. Acesso em: 13 ago. 2021. DOI: https://doi.org/10.15536/thema.14.2017.268-288.404.

FREEMAN, Scott et al. Active learning increases student performance in science, engineering, and mathematics. Proceedings of the National Academy of Sciences, Washington, v. 111, n. 23, p. 8410-8415, 2014. Disponível em: https://www.pnas.org/content/111/23/8410. Acesso em: 13 ago. 2021. DOI: https://doi.org/10.1073/pnas.1319030111.

FREITAS, Raquel Aparecida Marra da Madeira. Ensino por problemas: uma abordagem para o desenvolvimento do aluno. Educação e Pesquisa, São Paulo, v. 38, n. 2, p. 403-418, abr./jun. 2012. Disponível em: 
Julliane D. Yoneda, José Augusto Oliveira Huguenin

https://www.scielo.br/j/ep/a/sk8JPtqzGPdVN4jyTXyB7wd/?lang=pt\&format=pdf. Acesso em: 13 ago. 2021. DOI: https://doi.org/10.1590/S1517-97022011005000011.

FREIRE, Paulo. Pedagogia do oprimido. Rio de Janeiro: Paz e terra, 2013.

FREIRE, Paulo. Pedagogia da autonomia: saberes necessários à prática educativa. 51. ed. Rio de Janeiro: Paz e terra, 2015.

HOFFMANN, Jussara. Avaliação mediadora: uma prática em construção da pré-escola à universidade. Porto Alegre: Mediação, 2009.

JESUS, Filipe Augusto de. Em busca de soluções para evitar a evasão nos cursos de exatas da Universidade Federal de Sergipe: relatos de uma proposta da Química. Debates em Educação, Maceió, v. 7, n. 15, p. 34-55, 2015. Disponível em: https://www.seer.ufal.br/index.php/debateseducacao/article/view/974/1567. Acesso em: 13 ago. 2021. DOI: https://doi.org/10.28998/2175-6600.2015v7n14p33.

LEITE, Bruno Silva. Tecnologias no ensino de Química: teoria e prática na formação docente. Curitiba: Editora Appris, 2015.

LIMA, Érika Rossana Passos de Oliveira; MOITA, Filomena Maria Gonçalves da Silva Cordeiro. A tecnologia e o ensino de Química: jogos digitais como interface metodológica. Campina Grande: EDUEPB, 2011.

LIMA-JÚNIOR, Cláudio Gabriel et al. Sala de aula invertida no ensino de Química: planejamento, aplicação e avaliação no ensino médio. Revista Debates em Ensino de Química, Recife, v. 3, n. 2, p. 119-145, 2017. Disponível em: http://www.journals.ufrpe.br/index.php/REDEQUIM/issue/view/178. Acesso em: 13 ago. 2021.

MARTIN, Maria da Graça Moraes Braga; MARTINS, Luiza Pires Ribeiro. A sala de aula invertida e a sua relação com a Teoria de Mediação de Vygotsky. In: IV COLBEDUCA COLÓQUIO LUSO-BRASILEIRO DE EDUCAÇÃO, v. 3, 2018, Braga e Paredes de Coura, Portugal. Anais [...] Braga e Paredes de Coura, Portugal, 2018, p. 1-9. Disponível em: https://www.revistas.udesc.br/index.php/colbeduca/article/view/11462. Acesso em: 13 ago. 2021.

MAZUR, Eric. Can we teach computers to teach?. Computers in Physics, v. 5, p. 31-38, 1991. Disponível em: https://aip.scitation.org/doi/pdf/10.1063/1.4822968. Acesso em: 13 ago. 2021. DOI: https://doi.org/10.1063/1.4822968.

MELO, Ana Danielle de Queiroz; SALDANHA, Sabrina Maria Cordeiro. A retenção dos alunos da Licenciatura em Química do IFCE, campus Quixadá: uma análise. Educação, Escola \& Sociedade, Montes Claros, v. 13, n. 15, p. 1-16, 2020. Disponível em: https://www.periodicos.unimontes.br/index.php/rees/article/view/1980. Acesso em: 13 ago. 2021. DOI: https://doi.org/10.46551/ees.e202005.

MOREIRA, Marco Antonio. Teorias de aprendizagem. 2. ed. São Paulo: EPU, 2011. 
NEVES, Vanusa Nascimento Sabino; VALDEGIL, Daniel de Assis; SABINO, Raquel Nascimento. Ensino remoto emergencial durante a pandemia de covid-19 no Brasil: estado da arte. Revista Pemo, Fortaleza, v. 3, n. 2, e325271, 2021. Disponível em: https://revistas.uece.br/index.php/revpemo/article/view/5271. Acesso em: 13 ago. 2021. DOI: https://doi.org/10.47149/pemo.v3i2.5271.

NOVAK, Gregor; GAVRIN, Andrew; CRISTIAN, Wolfgang; PATTERSON, Evelyn. Just-in-time teaching: blending active learning with technology. New Jersey: Prentice Hall, 1999.

OLIVEIRA, Claudinei Osorio de; ROSSI, Alexandre; ALVES, Evandro Roberto. Ensino híbrido aplicado na revisão de ácido base de Arrhenius no ensino médio. Chemical Education in point of view, Foz do Iguaçu, v. 4, n. 1, p. 97-114, 2020. Disponível em:

https://revistas.unila.edu.br/eqpv/article/view/2383. Acesso em: 13 ago. 2021. DOI: https://doi.org/10.30705/eqpv.v4i1.2383.

OLAKANMI, Eunice Eyitayo. The effects of a flipped classroom model of instruction on students' performance and attitudes towards Chemistry. Journal of Science Education and Technology, v. 26, p. 127-137, 2017. Disponível em:

https://link.springer.com/article/10.1007/s10956-016-9657-x. Acesso em: 13 ago. 2021. DOI: https://doi.org/10.1007/s10956-016-9657-x.

PAIVA, Marlla Rúbya Ferreira; PARENTE, José Reginaldo Feijão; BRANDÃO, Israel Rocha; QUEIROZ, Ana Helena Bomfim. Metodologias ativas de ensino-aprendizagem: revisão integrativa. SANARE, Sobral, v. 15, n. 2, p. 145-153, 2016. Disponível em:

https://sanare.emnuvens.com.br/sanare/article/view/1049. Acesso em: 13 ago. 2021.

PALMEIRA, Robson Lima; RIBEIRO, Wagner Leite; SILVA, Andrezza Araújo Rodrigues da. As metodologias ativas de ensino e aprendizagem em tempos de pandemia: a utilização dos recursos tecnológicos na educação superior. HOLOS, Natal, v. 5, p. 1-13, 2020. Disponível em: https://www2.ifrn.edu.br/ojs/index.php/HOLOS/article/view/10810. Acesso em: 13 ago. 2021. DOI: https://doi.org/10.15628/holos.2020.10810.

RYAN, Michael D.; REID, Scott A. Impact of the flipped classroom on student performance and retention: a parallel controlled study in General Chemistry. Journal of Chemical Education, Washington, v. 93, n. 1, p. 13-23, 2016. Disponível em: https://pubs.acs.org/doi/abs/10.1021/acs.jchemed.5b00717. Acesso em: 13 ago. 2021. DOI: https://doi.org/10.1021/acs.jchemed.5b00717.

REID, Scott A. A flipped classroom redesign in General Chemistry. Chemistry Education Research and Practice, v. 17, n. 4, p. 914-922, 2016. Disponível em: https://pubs.rsc.org/en/content/articlelanding/2016/rp/c6rp00129g. Acesso em: 13 ago. 2021. DOI: https://doi.org/10.1039/C6RP00129G.

SANDES, Rafael Donizete Dutra; AMBROSIO, Renato Canha; ANGELUCCI, Camilo Andrea. Integração numérica de leis de velocidade diferenciais com o uso do SCILAB. Química Nova, São Paulo, v. 36, n. 1, p. 181-186, 2013. Disponível em: http://quimicanova.sbq.org.br/default.asp?ed=103. Acesso em: 13 ago. 2021. 
SANTOS, Débora Silva. Tecnologias de informação e comunicação (TICs): uma abordagem no ensino remoto de Química e Nanotecnologia nas escolas em tempos de distanciamento social. Revista Latino-Americana de Estudos Científicos, Salvador, v. 2, n. 7, p. 15-25, 2021. Disponível em: https://periodicos.ufes.br/ipa/article/view/33855. Acesso em: 13 ago. 2021.

SEERY, Michael; DONNELLY, Roisin. The implementation of pre-lecture resources to reduce in-class cognitive load: a case study for higher education chemistry. British Journal of Educational Technology, v. 43, n. 4, p. 667-677, 2012. Disponível em: http://eprints.teachingandlearning.ie/3685/. Acesso em: 13 ago. 2021. DOI: https://doi.org/10.1111/j.1467-8535.2011.01237.x.

SILVA, Bruna Rafaela Ferreira da; SILVA NETO, Sebastião Luiz da; LEITE, Bruno Silva. Sala de aula invertida no ensino de Química Orgânica. Química Nova, São Paulo, v. 44, n. 4, p. 493501, 2021. Disponível em: http://quimicanova.sbq.org.br/default.asp?ed=304. Acesso em: 13 ago. 2021. DOI: http://dx.doi.org/10.21577/0100-4042.20170677.

SWELLER, John. Cognitive load during problem solving: effects on learning. Cognitive Science. v.12, n. 2, p. 257-285, 1988. Disponível em:

https://onlinelibrary.wiley.com/doi/abs/10.1207/s15516709cog1202_4. Acesso em: 13 ago. 2021. DOI: https://doi.org/10.1207/s15516709cog1202_4.

TREVELIN, Ana Teresa Colenci; PEREIRA, Marco Antonio Alves; OLIVEIRA NETO, José Dutra de. A utilização da "sala de aula invertida" em cursos superiores de tecnologia: comparação entre o modelo tradicional e o modelo invertido "flipped classroom" adaptado aos estilos de aprendizagem. Revista de Estilos de Aprendizagem, Madrid, v. 12, n. 11, p. 1-14, 2013.

Disponível em: http://revistaestilosdeaprendizaje.com/article/view/992. Acesso em: 13 ago. 2021.

VYGOTSKY, Lev Semionovitch. A formação social da mente. 7. ed. São Paulo: Martins Fontes, 2007.

WEAVER, Gabriela C.; STURTEVANT, Hannah G. Design, implementation and evaluation of a flipped format General Chemistry Course. Journal of Chemical Education, Washington, v. 92, n. 9, p. 1437-1448, 2015. Disponível em:

https://pubs.acs.org/doi/abs/10.1021/acs.jchemed.5b00316?src=recsys. Acesso em: 13 ago. 2021. DOI: https://doi.org/10.1021/acs.jchemed.5b00316.

WIEMAN, Carl. PhET Interractive Simulations. University of Colorado Boulder. s/d. Disponível em: https://phet.colorado.edu/pt_BR/simulations/category/chemistry. Acesso em: 10 jun. 2021.

YONEDA, Julliane Diniz; HUGUENIN, José Augusto Oliveira. Proposta de sequência didática para a disciplina de Química Geral explorando o uso de tecnologias digitais. Revista Docência do Ensino Superior, Belo Horizonte, v. 8, n. 2, p. 60-77, 2018. Disponível em:

https://periodicos.ufmg.br/index.php/rdes/article/view/2519. Acesso em: 13 ago. 2021. DOI: https://doi.org/10.35699/2237-5864.2018.2519. 


\section{APÊNDICE}

\section{Questionário Final}

Deixe aqui suas considerações finais sobre o curso para nos ajudar a melhorá-lo futuramente. *Obrigatório

1. Levando em consideração que não havia outra possibilidade a não ser que o curso fosse remoto, que nota você daria para o mesmo? *

Marcar apenas uma oval.

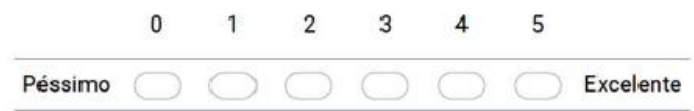

2. Comente os motivos da nota atribuida na pergunta anterior. *

3. Quanto você considera que aprendeu do conteúdo da disciplina de Quimica Geral? *

Marcar apenas uma oval.

\begin{tabular}{|c|c|c|c|c|c|c|c|}
\hline & 0 & 1 & 2 & 3 & 4 & 5 & \\
\hline Nada & & & & & 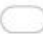 & 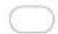 & Muito \\
\hline
\end{tabular}

4. O que você achou dos materiais e videos complementares? *

Marcar apenas uma oval.

Desnecessários

Me ajudaram um pouco

Me ajudaram bastante

Interessantes, mas não utilizei

Interessantes e complementaram bastante o conteúdo

5. A metodologia utilizada te incentivou a ficar até o final do curso? *

Marcar apenas uma oval.
Foi indiferente
Não me incentivou
Me incentivou um pouco
Me incentivau bastante

6. Comente os motivos da sua resposta anterior: * 
7. Cite pontos negativos da metodologia empregada: *

8. Cite pontos positivos da metodologia empregada: *

9. Você acha que a nossa troca de questionários semanais contribuiu para atender melhor as necessidades da turma? *

Marcar apenas uma oval.

$\bigcirc \operatorname{Sim}$

$\bigcirc$ Não

10. O que você achou dos testes semanais como parte da avaliação? *

Marcar apenas uma oval.

Não gostei

Gostei, pois não deixaram que a matéria acumulasse

Gostei, pois contribuiram para a nota final de forma positiva

Indiferenté

11. O que você achou das questões de ponto extra? *

Marcar apenas uma oval.

Não gostei

Gostei, pois me fizeram ver a aplicabilidade dos conteúdos estudados

Gostei, pois contribuiram para a nota final de forma positiva

Indiferente

12. A partir da experiência que você teve. que sugestões você daria para melharar este curso, caso ele continue sendo remoto no próximo semestre? *

Muito obrigada por sua contribuição! 


\section{Julliane D. Yoneda}

Engenheira Química, licenciada e doutora em Química, é professora do Departamento de Química do Instituto de Ciências Exatas da Universidade Federal Fluminense.

jullianeyoneda@id.uff.br

\section{José Augusto Oliveira Huguenin}

Bacharel, licenciado e doutor em Física, é professor do Departamento de Física do Instituto de Ciências Exatas da Universidade Federal Fluminense (UFF). É credenciado no Programa de Pós-graduação em Física da UFF e no Mestrado Nacional Profissional em Ensino de Física MNPEF Polo 15 UFF/IFRJ.

jose_huguenin@id.uff.br 